\title{
The Role of Hyperuricemia in the Pathogenesis and Progressivity of Chronic Kidney Disease
}

\author{
Gede Wira Mahadita*(D, Ketut Suwitra \\ Department of Internal Medicine, Nephrology and Hypertension Division, Faculty of Medicine, Udayana University, Sanglah \\ General Hospital, Denpasar, Bali, Indonesia
}

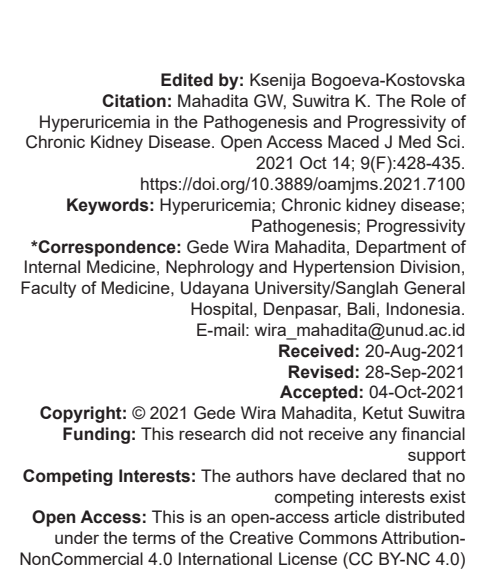

\section{Abstract}

In humans, the end product of purine metabolism is uric acid. Over $70 \%$ of uric acid is excreted through the kidneys. When renal function is impaired, uric acid secretion is also impaired. This directly correlates the prevalence of hyperuricemia with the severity of chronic kidney disease (CKD). It has been reported that the prevalence of hyperuricemia in patients with Stage I-III CKD is $40-60 \%$ and up to $70 \%$ in patients with Stage IV-V CKD. Some studies found a link between serum uric acid levels and decreased glomerular filtration rate (GFR), an independent risk factor for CKD development. Because CKD and serum uric acid levels are related, the relationship between the two frequently generates controversy. As such, this review of the literature discusses the role of uric acid in the pathogenesis and progression of CKD.

\section{Introduction}

The uric acid level in the serum is usually high in patients with chronic kidney disease (CKD). In patients with CKD, whether hyperuricemia is caused by impaired renal function or by hyperuricemia alone commonly arises. Although both conditions may have a reciprocal relationship, most research performed recently showed that uric acid is one of the independent predictors for CKD. Uric acid is considered a potential risk factor that plays a role in the progressivity of CKD.

Hyperuricemia and gout are two overlapping conditions. However, these two terms have distinct definitions and boundaries. Hyperuricemia is defined as serum uric acid level $>7 \mathrm{mg} / \mathrm{dl}$ in males and $>6 \mathrm{mg} / \mathrm{dl}$ in females [1]. Meanwhile, gout is a disorder in purine metabolism or uric acid excretion through the kidneys, which are indicated by: (a) Hyperuricemia; (b) accumulation of monosodium urate in the whole body with a predilection for the joints, joint cartilages, bones, bursas, subcutaneous tissues, and kidneys; (c) nephropathy; and (d) nephrolithiasis. On the other hand, CKD is defined as renal failure or glomerular filtration rate $\left(\right.$ GFR) $<60 \mathrm{ml} / \mathrm{min} / 1.73 \mathrm{~m}^{2}$ for 3 months or more regardless of the cause. Renal failure is indicated by microalbuminuria, that is, the ratio between albumin and creatinine is $>30 \mathrm{mg} / \mathrm{g}$ on 2 out of 3 urine specimens.

Gout's prevalence continues to rise each year, and it has become the most frequent inflammatory arthropathy. The prevalence of gout in the United States is estimated at approximately $3.9 \%$ and is primarily found in males rather than females (6.1 million vs. 2.2 million people) [2]. The most current prevalence of gout and hyperuricemia in Indonesia was $1.7 \%$ and $24.3 \%$ [3]. A similar fact is also found in CKD, where the global prevalence is $8-16 \%$ and $14 \%$ in the United States. On the other hand, the prevalence of CKD in Indonesia in 2005 was around $12.5 \%$, and in 2012, the number of new end-stage CKD patients was 19,621 people [4].

Uric acid is the final product of purine metabolism in humans. Reduced GFR contributes to hyperuricemia, which is typically encountered in patients with CKD [5]. The kidneys secrete $70 \%$ of uric acid, with the rest coming from the gastrointestinal tract. More than $90 \%$ of hyperuricemia cases occurred due to disorders in renal secretion function. The prevalence of hyperuricemia is parallel with the reduction of GFR, 40-60\% occurred in Stage I-III CKD patients, and 79\% occurred in Stage IV-V CKD [6]. 
The largest study to date on the relationship between hyperuricemia and CKD with a 25-year follow-up period, which used samples from the US Renal Data System, discovered that subjects in the highest quartile of uric acid had the highest hazard ratio of around 2.4 to develop CKD [7], [8]. Bellomo et al. [9] found the relationship between uric acid and GFR reduction in a prospective cohort study that involved 900 normotensive subjects. Increased uric acid levels were associated with deterioration of renal function, and this connection remained significant after adjustment for $\mathrm{BMI}$, blood pressure, and urine albumin-creatinine ratio factors. Another study, which included 21,475 healthy people (no comorbidities) with a median follow-up of roughly seven years, found that uric acid level in the serum was an independent risk factor for new-onset renal disease [10]. Atherosclerosis risk in communities and the cardiovascular Health Study, which included 13,338 samples with normal renal function, revealed that increased uric acid level was an independent risk factor for CKD [11].

Initially, it was assumed that the only mechanism linking hyperuricemia and CKD was the development of uric acid crystals on the surface of kidney epithelial cells and the promotion of inflammatory processes that would eventually accelerate the deterioration in kidney function [12]. However, even without forming uric acid crystals, hyperuricemia acts as a risk factor for CKD development. It accelerates the progression of patients with CKD by activating the renin-angiotensin system (RAS) and increasing oxidative stress associated with glomerular hypertension and renal autoregulation failure [13]. Among gout patients, $25 \%$ have proteinuria, $50 \%$ notice a decrease in renal function, and $25 \%$ develop end-stage renal failure. The autopsy and biopsy revealed arteriosclerosis, glomerulosclerosis, and tubulointerstitial fibrosis [12].

This literature review was conducted to explore the role of uric acid in CKD events and underline that serum uric acid, through its different processes, acts as an independent risk factor for CKD, not just as a marker for impaired uric acid excretion function through the kidneys in CKD.

After introduction should be method, the part below should be merged in introduction.

\section{Pathophysiology of Hyperuricemia}

Uric acid is a weak acid trioxopurine that is primarily synthesized in the liver, muscles, and gastrointestinal tract. It is composed of a substructure of pyrimidine and imidazole with oxygen molecules [14]. The precursor to uric acid is xanthine, converted to uric acid through the xanthine oxidoreductase enzyme. Exogenous uric acid is obtained through meals, particularly fatty meats and internal organs, whereas endogenous purines are synthesized within the human body. Hyperuricemia is caused by insufficient excretion, excessive production, or a combination of the two. Uric acid homeostasis is presented in Figure 1.

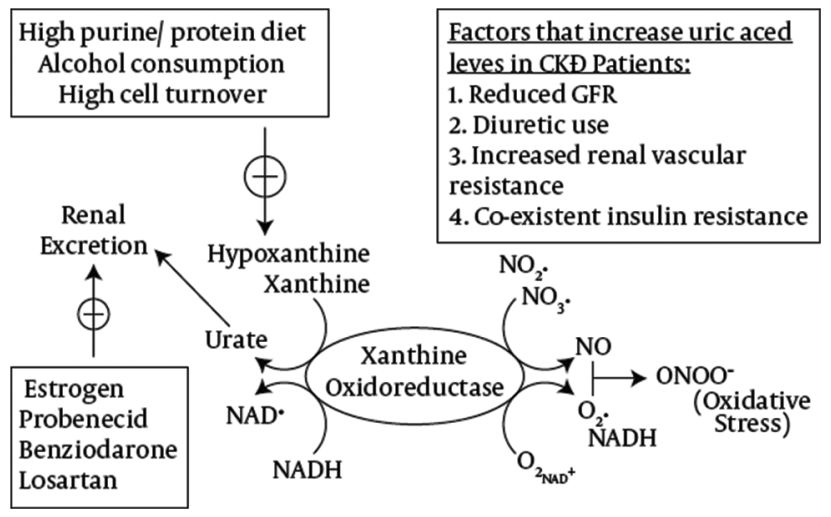

Figure 1: Schematic of uric acid homeostasis [15]

Uric acid is filtered, reabsorbed, secreted in the glomerulus, and then reabsorbed in the proximal tubules. Under normal circumstances, the kidneys excrete approximately $250-750 \mathrm{mg}$ of uric acid each day, or about $70 \%$ of it. This mechanism is primarily controlled by the urate transporter (URAT1), which is found in the brush-border membrane of the kidneys, particularly in segments 1 and 2 of the proximal tubules, and is inhibited by angiotensin II receptor blockers (Figure 2) [16]. There are several stages of uric acid handling by the kidneys, including filtration, reabsorption, and secretion in the glomerulus, and in the final stage will undergo post-secretion reabsorption [15]. Although urate (the form of uric acid at blood $\mathrm{pH}$ of 7.4) is freely filtered in the glomerulus, the urate excretion fraction is only $8-10 \%$ due to reabsorption in this proximal tubule [12]. Changes in uric acid excretion can occur due to decreased glomerular filtration, tubular secretion, or increased tubular reabsorption.

In addition to the decrease in renal excretion function, uric acid can also occur due to increased degradation of skeletal muscle ATP resulting in type III, IV, and VII glycogen [17]. This condition can occur due to excessive alcohol consumption, which triggers the breakdown of ATP by the liver resulting in organic acids competing with uric acid in the excretion process in the tubules. Enzymatic defects, such as aldolase-B deficiency, can cause hyperuricemia by a combined mechanism between overproduction and underexcretion.

\section{Pathophysiology of Kidney Damage in Hyperuricemia}

Chronic gout and severe hyperuricemia are associated with the accumulation of uric acid crystals in the renal medulla. However, some research 


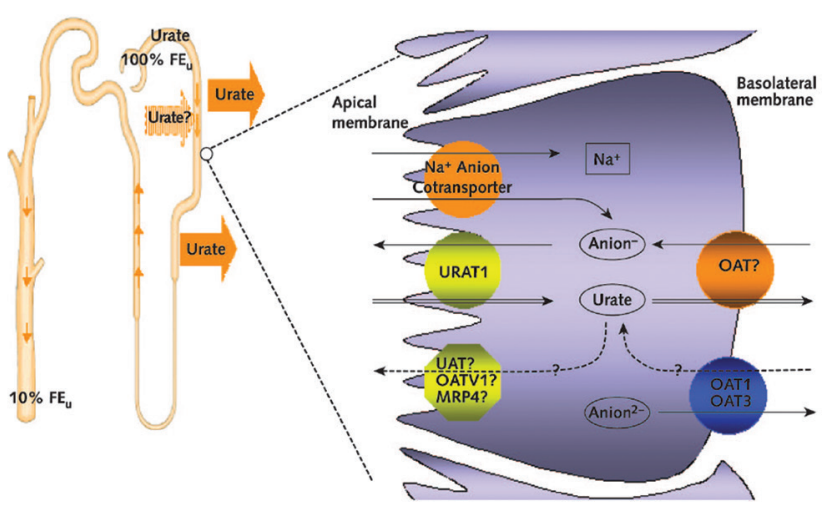

Figure 2: Mechanism of urate transportation in the kidneys [16]

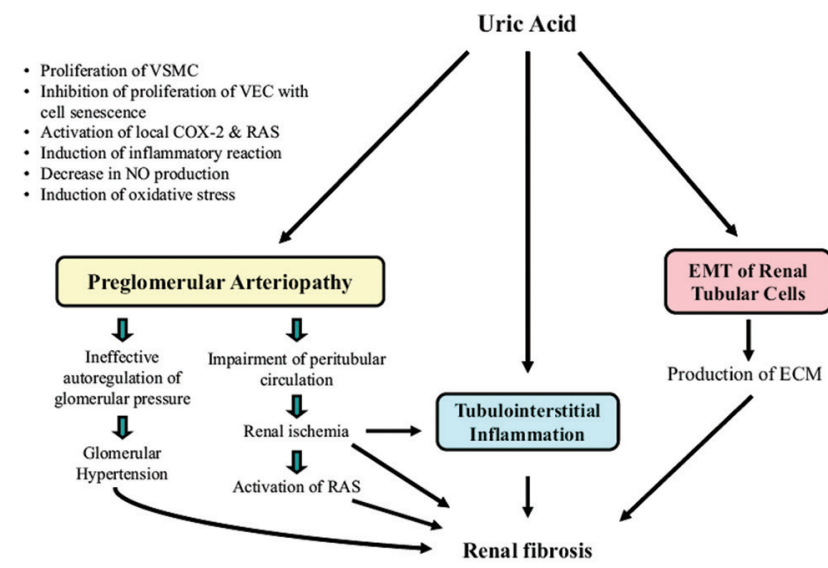

Figure 3: Molecular mechanism of uric acid in conjunction with chronic kidney disease [19]

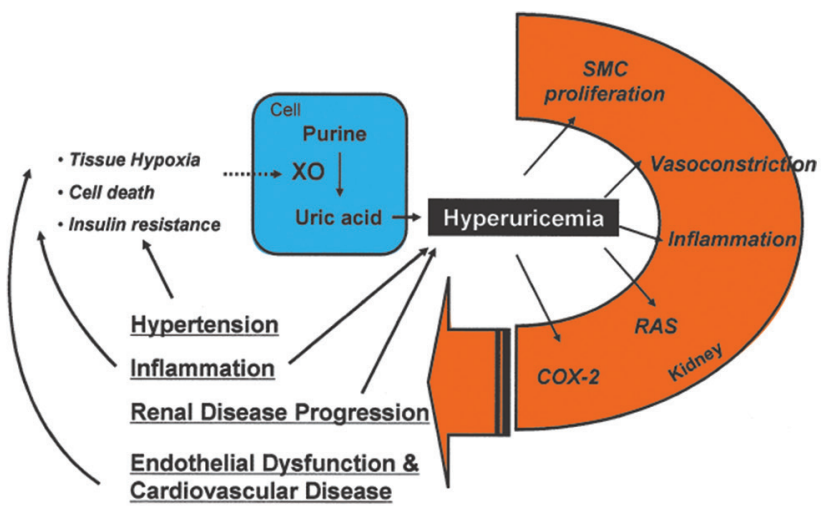

Figure 4: The reciprocal relationship between hyperuricemia, hypertension, and chronic kidney disease progressivity [19]

suggests that chronic hyperuricemia (without going through the formation of uric acid crystals in the kidneys) can cause chronic kidney injuries through RAS activation and induce oxidative stress, resulting in glomerular hypertension and impaired renal function autoregulation [18]. In the extracellular environment, uric acid plays a role as an antioxidant, but inside the cells, uric acid has a pro-oxidant effect which causes endothelial and mitochondrial dysfunction.

Uric acid can cause CKD either directly or indirectly. It can directly cause CKD through the formation of uric acid crystals or RAS activation and increases oxidative stress, which results in glomerular hypertension, auto-regulation failure of the kidneys, and endothelial and mitochondrial dysfunction. Uric acid can indirectly cause CKD by secondarily decreasing kidney function through obesity and insulin resistance.

\section{Direct mechanism of relationship between hyperuricemia and CKD}

Uric acid can cause preglomerular artery disease, inflammation of the kidneys, and hypertension through activation of RAS and cyclooxygenase-2 (COX-2). In hyperuricemia, smooth muscle cells multiply, indicating that uric acid has a mitogenic effect on smooth muscle cells [19]. Uric acid, through COX-2, angiotensin II, and thromboxane, has been shown in animal studies to promote the proliferation of smooth muscle cells in blood vessels, ensuing in hypertension and progressive CKD [20]. Uric acid can cause vasculopathy in the systemic blood arteries and the kidneys by activating COX-2, angiotensin II, and thromboxane. Thickening of afferent arterioles and macrophage infiltration on the walls of blood vessels will increase preglomerular vasculopathy, which will eventually cause ischemia, thus initiating chronic injuries in the kidneys. Vasculopathy also results in ineffective autoregulation function in the kidneys and increases systemic pressure transfer in the glomerulus (Figures 3 and 4) [19].

Uric acid can activate phospholipase A2 and nuclear transcription factor- $\kappa \beta$ (NF- $\kappa \mathrm{B})$, which causes increased production of pro-inflammatory cytokines, resulting in inhibition of cellular proliferation of proximal tubules in vitro [21]. Increased uric acid will be accompanied by increased production of proinflammatory cytokines, such as tumor necrosis factor- $\alpha$, c-reactive protein, and expression of various local chemokines, such as monocyte chemotactic protein-1 in the kidneys and COX-2 in blood vessels [19], [22]. Monocyte chemotactic protein-1 can also help increase the transport of uric acid directly into the smooth muscle cells of blood vessels to re-activate transcription factors $\mathrm{NF}-\kappa \mathrm{B}$ and mitogen-activated protein kinase [23].

Discontinuation of drugs that can lower uric acid was related to the increased urinary transforming growth factor- $\beta 1$ in CKD patients with hyperuricemia [24]. This series of processes underlie the relationship of hyperuricemia in causing chronic inflammation of the kidneys. Uric acid is known to directly affect tubule cells by inducing the transition of epithelial cells into mesenchymal cells or referred to as epithelial-to-mesenchymal transition (EMT). EMT is the initial stage in the process of fibrosis in the kidneys [25]. EMT will accelerate the occurrence of glomerular hypertension and vascular lesions, and therefore resulting in proteinuria and renal failure in conjunction with worsening of glomerulosclerosis condition and tubulointerstitial disease [19]. 


\section{Indirect mechanisms of the relationship between hyperuricemia and CKD through metabolic syndrome (MS)}

Increased uric acid levels can result in oxidative stress and endothelial dysfunction, resulting in glomerular and systemic hypertension, which resulted in increased vascular resistance and decreased kidney perfusion [26]. Increased uric acid will stimulate the oxidation of low-density lipoprotein, resulting in lipid peroxidation. Specifically, oxidative stress due to hyperuricemia reacts and lowers nitric oxide (NO) levels, resulting in failure of $\mathrm{NO}$ release response to acetylcholine and decreased endothelial vasodilation ability [27].

Obesity and MS are the main risk factors for CKD. They are strongly associated with hyperuricemia as a consequence of insulin resistance, which has an impact on decreasing urate excretion through the kidneys [26]. Uric acid inhibits NO synthase, lowering the NO level, which contributes to the development of MS. A high level of uric acid is often found in people with hypertension. Increased uric acid levels can result in initial salt-insensitive hypertension, which is reversible when the uric acid level becomes normal [28].

Hyperuricemia with chronic and low-grade inflammatory effects can affect the phosphorylation of insulin receptors in threonine residue instead of tyrosine residue, thus triggering a decrease in insulin receptor sensitivity, which eventually leads to insulin resistance. Insulin resistance is associated with aciduria, which will accelerate the formation of nephrolithiasis due to uric acid [27].

\section{Manifestations of Kidney Disease in Hyperuricemia}

Manifestations of kidney disease concerning hyperuricemia include uric acid nephrolithiasis, urate nephropathy, and chronic uric acid nephropathy. In gout patients, the primary abnormality which affects the formation of uric acid stones in the kidneys is an increase in the acidity of urine that can trigger the formation of uric acid crystals [29]. Increased acidity of urine is associated with an increased risk of the construction of uric acid stones and a decrease in ammonium excretion. MS is comorbid and is considered strong enough to play a role in the incidence of uric acid nephrolithiasis since insulin resistance can increase the degree of acidity of the urine.

Urate nephropathy is defined as the deposition of uric acid crystals at physiological $\mathrm{pH}$ in the renal medulla. The accumulation of uric acid crystals will trigger inflammatory processes and fibrosis in the surrounding tissues [29]. The pathological spectrum associated with urate nephropathy can be heavy arteriosclerosis, glomerulosclerosis, and interstitial fibrosis. On the other hand, impaired renal function associated with chronic hyperuricemia can also occur without uric acid crystals. Hyperuricemia itself can be a de novo risk factor for CKD [10]. In the broader terminology, this condition is referred to as chronic uric acid nephropathy [29]. Impaired renal function is found in $30-50 \%$ of patients who have been suffering from gout for several years, and in $90 \%$ of patients, changes of the histological image were found in kidney biopsies. The most common histological findings are arteriosclerosis, focal or global glomerulosclerosis, and chronic tubulointerstitial disease.

\section{Diagnostics of Kidney Damage Due to Hyperuricemia}

Chronic uric acid nephropathy is characterized by mild proteinuria, less urine sediment, and minor tubular dysfunction (usually in the form of failure of urine concentrating, which is manifested as isosthenuria). The possibility of urate nephropathy diagnosis should be considered when it is found that serum uric acid increase is disproportioned with decreased renal function level, as presented in Table 1 [29]. Uric acid levels higher than those shown in Table 1, which correspond to serum creatinine (SC) levels, can be suspected as chronic uric acid nephropathy. However, it is not a confirmed diagnosis.

Table 1: SC and uric acid levels in CKD [29]

\begin{tabular}{lllll}
\hline $\mathrm{SC}$ & & & Serum uric acid & \\
\cline { 5 - 5 } $\mathrm{mg} / \mathrm{dl}$ & $\mu \mathrm{mol} / \mathrm{l}$ & & 9 & $\mu \mathrm{mol} / \mathrm{I}$ \\
\hline$<1.5$ & $<132$ & & 10 & 536 \\
$1.5-2$ & $132-176$ & 12 & 595 \\
$>2$ & $>176$ & & & 714 \\
\hline SC: Serum creatinine. & &
\end{tabular}

Symptoms of hyperuricemia that cause gout, such as joint pain, usually on the fingers, should also be explored. The joints appear to have swelling, redness, and pain that will get worse. Gout can also occur on the ankles, knees, and wrists [15]. When performing a physical examination, a thorough examination should be made to see any presence of pain in the joints. Anamnesis should be done in detail on the pain and inflammation to ensure that hyperuricemia originates from gout, and serum uric acid levels should be tested.

From the histopathological aspect, the most found histological images are arteriosclerosis, focal or global glomerulosclerosis, and chronic tubulointerstitial disease. Uric acid crystals are sometimes found in the tubules and interstitium (Figure 5), especially in the outer medulla. 


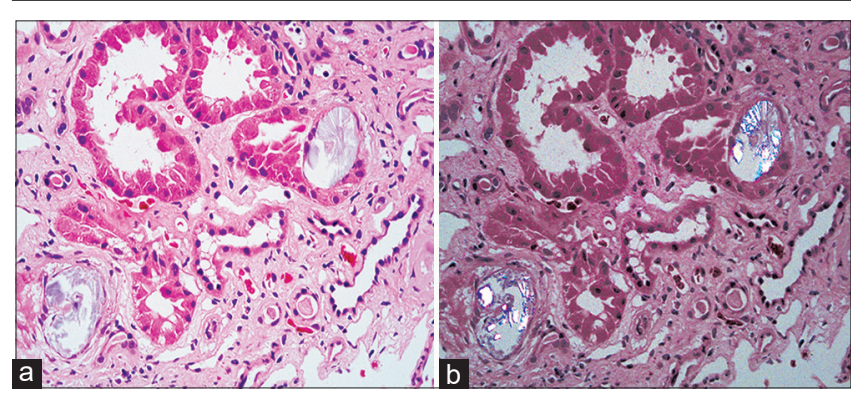

Figure 5: Histopathological findings on chronic uric acid nephropathy. (a) Fragments of uric acid crystals in atrophic tubules; (b) clearer crystal image with polarized lighting [29]

\section{Management}

Some research showed the benefits of decreasing uric acid levels on improved kidney function. A prospective study with a randomized controlled trial (RCT) design showed that allopurinol therapy was associated with GFR improvement in CKD. However, it showed no improvement in the primary endpoint, that is, end-stage renal disease [30]. Discontinuation of allopurinol administration in CKD patients with stable conditions was associated with worsening hypertensive disorders and accelerating CKD's progressivity, especially in patients who did not receive ACE inhibitor therapy [24]. Decreased uric acid levels in patients with asymptomatic hyperuricemia were also associated with improvement of GFR [31]. Some studies also showed that reducing uric acid will lower the risk of cardiovascular disease in patients with CKD [31], [32]. In an RCT conducted by Siu et al. [33], patients with mild to moderate CKD were randomized to get allopurinol (100-300 mg/day to achieve normal serum uric acid levels). The control group did not receive any treatment to the lower uric acid levels. After a 12-month follow-up, it was found that the control group experienced a more remarkable and significant increase in SC ( $>40 \%$ of the sample). The proportion of having dialysis and death was also more significant. A meta-analysis study by Wang et al. [34] concluded that a decrease in uric acid levels is associated with a reduction of SC and an increase in GFR. Similar findings were observed in the J-HEALTH study, which involved 7629 subjects, where GFR changes were negatively related to the better uric acid level and cardiovascular outcome [35].

In several studies, allopurinol was also found to have beneficial effects on other cardiovascular parameters in patients with CKD. Some facts from the results showed that decreased uric acid levels also inhibit the RAS system. Uric acid can stimulate the production of angiotensin II in blood vessel cells and increase renin expression in experimental animals [36]. Serum uric acid was also associated with increased renin and intrarenal RAS activation levels in humans [37]. A study by Feig et al. [18] found that managing hyperuricemia in patients with hypertension is associated with improved blood pressure. Allopurinol administration to the lower uric acid has a secondary effect, such as a significant decrease in systolic and diastolic blood pressure. Administration of allopurinol at a dose of $300 \mathrm{mg} /$ day for 3 months in patients with GFR $\geq 60 \mathrm{ml} / \mathrm{min} / 1.73 \mathrm{~m}^{2}$ can improve GFR and blood pressure (systole and diastole) [31].

Administration of allopurinol in the management of hyperuricemia with CKD must be done carefully. Accumulation of xanthine in the kidneys can occur following treatment with the xanthine oxidase inhibitor allopurinol, and this xanthine deposition can also induce the onset of acute renal disorders. To alleviate this condition, start with 50-100 mg/day of allopurinol and gradually increase to $200-300 \mathrm{mg} /$ day if tolerated. Other side effects of allopurinol, such as hypersensitivity reactions and Steven-Johnson syndrome, are found in renal failure patients given allopurinol. On the other hand, new xanthine oxidase inhibitors, such as febuxostat, do not require dose adjustment in renal failure with lesser side effects. However, further elaboration and research are still needed to use them as a primary therapeutic option. An RCT was conducted by Schumacher et al. [38], which involved 1072 patients with gout, uric acid $>8 \mathrm{mg} / \mathrm{dl}$ with normal SC levels or in the range of $1.5-2 \mathrm{mg} / \mathrm{dL}$. The subjects in this study were randomized into three groups, that is, the group who received febuxostat (with dose up to $240 \mathrm{mg} /$ day) and allopurinol (100-300 mg/day) or the group who received placebo. It was found that the febuxostat group has a higher percentage of subjects with an impaired renal function who achieved the uric acid targets compared to those who received allopurinol.

In general, hyperuricemia conditions associated with CKD are divided into (a) lowering uric acid to treat gout in CKD and (b) lowering uric acid to manage CKD. Guideline from American College of Rheumatology (ACR) in 2012 emphasized the importance of pharmacological and nonpharmacological management of gout in CKD. According to this recommendation, the target level of uric acid should be $6 \mathrm{mg} / \mathrm{dL}$ [7].

The drugs of choice for lowering uric acid levels are allopurinol and febuxostat. Febuxostat does not require dose adjustment in CKD patients. However, its safety profile on CKD patients in stage 4 and above is still minimal. The recommended initial dose of allopurinol in CKD is no more than $100 \mathrm{mg} /$ day. Then the dose can be titrated up to $300 \mathrm{mg} /$ day. ACR recommends giving prophylactic when initiating uric-acid-lowering drugs in gout patients to prevent exacerbations. The first drug of choice for this purpose is low-dose colchicine $(0.6 \mathrm{mg}$ twice daily, with lower doses for moderate to severe CKD (GFR 15-59 ml/min/1.73 $\mathrm{m}^{2}$ ). The use of NSAIDs should be avoided in CKD patients [7].

The research results on the relationship between CKD and hyperuricemia showed that 
Table 2: Interventional studies to the lower serum uric acid in CKD

\begin{tabular}{|c|c|c|c|c|}
\hline Study & Design and population & Intervention & Outcome & Main findings \\
\hline Siu et al. [33] & $\begin{array}{l}\text { RCT, } 54 \text { patients with hyperuricemia and } \\
\text { mild-to-moderate CKD (stage 2-3) }\end{array}$ & $\begin{array}{l}\text { Allopurinol } 100-300 \mathrm{mg} / \mathrm{day} \\
\text { versus no medications for } \\
12 \text { months }\end{array}$ & $\begin{array}{l}\text { Decrease in renal } \\
\text { function, initiation of } \\
\text { dialysis, or death }\end{array}$ & $\begin{array}{l}\text { The combined outcome is more remarkable and } \\
\text { more significant in the control group } 46 \% \text { versus } \\
16 \%(p=0.015)\end{array}$ \\
\hline Goicoechea et al. [30] & $\begin{array}{l}\mathrm{RCT}, 113 \text { hyperuricemia patients with } \\
\text { mild-to-moderate } \mathrm{CKD}\end{array}$ & $\begin{array}{l}\text { Allopurinol } 100 \mathrm{mg} / \mathrm{day} \\
\text { for } 24 \text { months versus no } \\
\text { medications (control) }\end{array}$ & $\begin{array}{l}\text { Progressivity of CKD } \\
\text { (operationally defined } \\
\text { by } \downarrow \text { GFR }>0.2 / \text { month), } \\
\text { cardiovascular events, } \\
\text { death }\end{array}$ & $\begin{array}{l}\Delta G F R \text { of control group }-3.3 \pm 1.2 \text {; intervention group } \\
1-3 \pm 1.3 ; P=0.018 ; \text { compared to the control group, } \\
\text { intervention with allopurinol was slowing down the } \\
\text { progressivity of } C K D \text { in Cox regression analysis } \\
\text { (control towards the age, gender, DM, uric acid) and } \\
\text { decrease in cardiovascular events (HR } 0.29 ; 95 \% \\
C l 0.09-0.86 ; P=0.026 \text { ) }\end{array}$ \\
\hline Kanbay et al. [31] & $\begin{array}{l}\text { Controlled cases, } 59 \text { patients with hyperuricemia } \\
\text { GFR }>60 \mathrm{ml} / \mathrm{min} \text { and normouricemia as the } \\
\text { control; only hyperuricemia patients received } \\
\text { allopurinol }\end{array}$ & $\begin{array}{l}\text { Allopurinol } 300 \mathrm{mg} / \text { day for } \\
3 \text { months }\end{array}$ & GFR $<60$ & $\begin{array}{l}\text { GFR increases significantly (from } 79.2 \pm 32 \text { to } 92.9 \\
\pm 37 ; \mathrm{P}=0.008 \text { ) in the intervention group, while no } \\
\text { increase in the control group }\end{array}$ \\
\hline Talaat and Sheikh [24] & $\begin{array}{l}\text { Interventional trial with discontinuation of } \\
\text { allopurinol in } 50 \text { hyperuricemia patients with stage } \\
3-4 \text { CKD, who were managed with allopurinol }\end{array}$ & $\begin{array}{l}\text { Discontinuation of allopurinol } \\
\text { for } 12 \text { months }\end{array}$ & $\begin{array}{l}\text { Changes in the LFG } \\
\text { and TGF beta } 1 \text { in } \\
\text { the urine }\end{array}$ & $\begin{array}{l}\text { Acceleration in the decrease of GFR and the } \\
\text { increase of blood pressure and TGF beta } 1 \text { is only } \\
\text { found in patients who did not receive ACE inhibitor }\end{array}$ \\
\hline Maio et al. [39] & $\begin{array}{l}\text { Placebo-controlled RCT on patients who were } \\
\text { treated with losartan during post hoc analysis } \\
\text { of RENAAL study; } N=1,342 \text { patients with type } 2 \\
\text { diabetes mellitus (DMO and nephropathy }\end{array}$ & $\begin{array}{l}\text { Post hoc analysis after the } \\
\text { first } 6 \text { months of treatment }\end{array}$ & $\begin{array}{l}\text { Progressivity of CKD } \\
\text { (defined as two-fold } \\
\text { increase of serum SC } \\
\text { or end-stage CKD) }\end{array}$ & $\begin{array}{l}\text { Losartan decreased uric acid } 0.16 \mathrm{mg} / \mathrm{dl}(95 \% \mathrm{Cl} \\
0.3-0.01)(\mathrm{p}=0.031) \text { versus placebo; the risk of } \\
\mathrm{CKD} \text { was } 6 \% \text { decreased }(95 \% \mathrm{Cl} 10-3 \%) \text { for each } \\
0.5 \mathrm{mg} / \mathrm{dl} \text { decrease of serum uric acid }\end{array}$ \\
\hline
\end{tabular}

the decrease in uric acid levels is related to the improvement of CKD progressivity. Most of the research data presented above in the previous section of discussions are observational studies, and some are clinical trial studies with relatively small samples. As the final part of this literature review, we tried to conduct a systematic review of the PubMed database on the studies of hyperuricemia and CKD interventions and their benefits. We found five studies relevant to this topic, as presented in Table 2.

\section{Conclusion}

Hyperuricemia is often found in CKD patients. Various studies have found that uric acid plays a role in the pathogenesis and progressivity of CKD. Uric acid can directly or indirectly cause CKD. Uric acid directly induces CKD through the formation of uric acid crystals or the activation of RAS. It increases oxidative stress, which results in glomerular hypertension, autoregulation failure of the kidneys, and endothelial and mitochondrial dysfunction. Uric acid indirectly causes CKD by decreasing kidney function secondarily through obesity and insulin resistance. This series of pathogenesis processes results in several manifestations of kidney disease in conjunction with hyperuricemia, including uric acid nephropathy and/or chronic uric acid nephropathy.

In patients with chronic uric acid nephropathy which accompanied by manifestations of hypertension with mild renal function disorders, mild proteinuria, less prominent urine sediment, and minor tubular dysfunction (usually in the form of failure of urine concentrating, which manifests as isosthenuria). The possibility of a diagnosis of urate nephropathy should be considered when a disproportion was found between the increase of serum uric acid and the decrease in renal function. From the histopathological aspect, the most common histological images are hyperuricemia frequently observed in patients with CKD. Numerous studies have established that uric acid plays a role in the pathogenesis and progression of CKD. Uric acid can cause CKD either directly or indirectly. Uric acid causes CKD directly by precipitating uric acid crystals or activating the RAS and increasing oxidative stress, resulting in glomerular hypertension, kidney autoregulation failure, and endothelial and mitochondrial dysfunction. Uric acid indirectly contributes to CKD by impairing kidney function secondary to obesity and insulin resistance. This cascade of pathogenesis events results in various kidney disease manifestations in association with hyperuricemia, including uric acid nephropathy and chronic uric acid nephropathy, arteriosclerosis, focal or global glomerulosclerosis, and chronic tubulointerstitial disease. Uric acid crystals are sometimes found in the tubules and interstitium, especially in the outer medulla.

Allopurinol should be used carefully in the treatment of hyperuricemia in patients with CKD. Accumulation of xanthine in the kidneys can occur during the administration of xanthine oxidase inhibitor allopurinol and this deposition of xanthine can also trigger the occurrence of acute renal disorders. To minimize this condition, the recommended initiation dose of allopurinol is 50-100 mg/day, and then increased to 200-300 mg/day after a few weeks if it is well-tolerated.

\section{References}

1. Peronato G. Purine metabolism and hyperuricemic states. In: Ronco C, Rodeghiero F, editors. Hyperuricemic Syndromes: Pathophysiology and Therapy. Switzerland: Karger; 2005. p. 1-21.

2. Zhu Y, Pandya BJ, Choi HK. Prevalence of Gout and hyperuricemia in The US general population: The national health and nutrition examination survey 2007-2008. Arthritis Rheum. 2011;63(10):3136-41. https://doi.org/10.1002/art.30520 


\section{PMid:21800283}

3. Dharmawan J, Valkenburg HA, Muirden KD, Wigley RD. The epidemiology of gout and hyperuricemia in rural population of java. J Rheumatol. 1992;19(10):1595-9.

PMid: 1464874

4. Indonesian Renal Registry. Report of Indonesian Renal Registry. $5^{\text {th }}$ ed. Jakarta: Perhimpunan Nefrologi Indonesia; 2012. p. $1-40$.

5. Nashar K and Fried LF. Hyperuricemia and the progression of chronic kidney disease: Is uric acid a marker or an independent risk factor? Adv Chronic Kidney Dis. 2012;19(6):386-91. https:// doi.org/10.1053/j.ackd.2012.05.004

PMid:23089273

6. Madero M, Sarnak MJ, Wang X, Greene T, Beck GJ, Kusek JW. Uric acid and long-term outcome in CKD. Am J Kidney Dis. 2009;53(5):796-803. https://doi.org/10.1053/j.ajkd.2008.12.021 PMid: 19303683

7. Khanna D, Fitzgerald JD, Khanna PP. 2012 American college of rheumatology guideline for management of gout. Part 1: Systematic nonpharmacologic and pharmacologic therapeutic approaches to hyperuricemia. Arthritis Care Res. 2012;64(10):1431-46. https://doi.org/10.1002/acr.21772 PMid:23024028

8. Hsu CY, Iribarren C, McCulloch CE. Risk factors for end-stage renal disease: 25 years follow-up. Arch Intern Med. 2009;169(4):342-50. https://doi.org/10.1001/archinternmed.2008.605

PMid:19237717

9. Bellomo G, Venanzi S, Verdura C. Association of uric acid with change in kidney function in healthy normotensive individuals. Am J Kidney Dis. 2010;56(2):264-72. https://doi.org/10.1053/j. ajkd.2010.01.019 PMid:20385436

10. Obermayr RP, Temml C, Gutjahr G. Elevated uric acid increase the risk for kidney disease. J Am Soc Nephrol. 2008;19(12):2407-13. https://doi.org/10.1681/ASN.2008010080 PMid: 18799720

11. Weiner DE, Tighiouart $\mathrm{H}$, Elsayed EF. Uric acid and incident kidney disease in the community. J Am Soc Nephrol. 2008;19(6):1204-11. https://doi.org/10.1681/ASN.2007101075 PMid:18337481

12. Khang $\mathrm{DH}$, Chen W. Uric acid and chronic kidney disease: New understanding of an old problem. Semin Nephrol. 2011;31(5):44752. https://doi.org/10.1016/j.semnephrol.2011.08.009 PMid:22000652

13. Feig DI, Kang DH, Johson RJ. Uric acid and cardiovascular risk. N Engl J Med. 2008;359(17):1811-21. https://doi.org/10.1056/ NEJMra0800885 PMid:18946066

14. Hediger MA, Johnson RJ, Miyazaki H. Molecular physiology of urate transport. Physiology. 2005;20:125-33. https://doi. org/10.1152/physiol.00039.2004 PMid:15772301

15. SahOM, QingYK.Association betweenhyperuricemiaandchronic kidney disease: A review. Nephrol Urol Mon. 2015;7(3):e27233. https://doi.org/10.5812/numonthly.7(3)2015.27233 PMid:26290849

16. Choi HK, Mount DB, Reginato AM. Pathogenesis of Gout. Ann Intern Med. 2005;143(7):499-516. https://doi.org/10.3949/ ccjm.75.suppl_5.s2 PMid:16204163

17. Shirashi $\mathrm{H}$, Une $\mathrm{H}$. The effect of the interaction between obesity and drinking on hyperuricemia in Japanese male office workers. J Epidemiol. 2009;19(1):12-6. https://doi.org/10.2188/jea. je20080016
PMid: 19164873

18. Feig DI, Soletsky B, Johnson RJ. Effect of allopurinol on blood pressure of adoloscent with newly diagnosed essential hypertension: A randomized trial. JAMA. 2008;300(8):924-32. https://doi.org/10.1001/jama.300.8.924 PMid:18728266

19. Kang DH, Nakagawa T, Feng L, Watanabe S, Han L, Mazzal $M$. A role for uric acid in the progression for renal disease. J Am Soc Nephrol. 2002;13(12):2888-97. https://doi.org/10.1097/01. asn.0000034910.58454.fd PMid:12444207

20. Nakagawa T, Mazzali M, Kang DH. Hyperuricemia causes glomerular hypertrophy in the rat. Am J Nephrol. 2003;23:2-7. https://doi.org/10.1159/000066303

PMid:12373074

21. Han HJ, Lim MJ, Lee YJ, Lee JH, Yang IS, Taub M. Uric acid inhibits renal proximal tubule cell proliferation via at least two signaling pathway involving PKC, MAPK, CPLA2 and NF-kappaB. Am J Physiol Renal Physiol. 2007;292(1):F373-81. https://doi.org/10.1152/ajprenal.00104.2006 PMid: 16985215

22. Mazzali M, Kanellis J, Han L, Feng L, Xia YY, Chen Q. Hyperuricemia induces a primary renal arteriolopathy in rats by a blood pressure-independent mechanism. Am J Physiol Renal Physiol. 2002;282(6):F991-7. https://doi.org/10.1152/ ajprenal.00283.2001 PMid:11997315

23. Kennelis J, Watanabe S, Li JH. Uric acid stimulates monocyte chemoattractant protein-1 production in vascular smooth muscle cells via mitogen-activated protein kinase and cyclooxigenase-2. Hypertension. 2003;41(6):1287-93. https://doi.org/10.1161/01. HYP.0000072820.07472.3B PMid: 12743010

24. Talaat KM, Sheikh AR. The effect of mild hyperuricemia on urinary transforming growth factor beta and the progression of chronic kidney disease. Am J Nephrol. 2007;27(5):435-40. https://doi.org/10.1159/000105142 PMid: 17622758

25. Zeisberg M, Kalluri R. The role of epithelial-to-mesenchyma transition in renal fibrosis. J Mol Med. 2004;82(3):175-81. https://doi.org/10.1007/s00109-003-0517-9 PMid:14752606

26. Lozada LG, Soto V, Tapia E, Casado C, Sautin YY, Nakagawa T. Role of oxidative stress in the renal abnormalities induced by experimental hyperuricemia. Am J Physiol Renal Physiol. 2008;292(4):F1134-41. https://doi.org/10.1152 ajprenal.00104.2008 PMid:18701632

27. Johnson RJ, Kang DH, Feig D, Kivlighn S, Kanellis J, Watanabe S et al. Is there a pathogenic role for uric acid in hypertension and cardiovascular disease? Hypertension. 2003;41(6):1183-90. https://doi.org/10.1161/01.HYP.0000069700.62727.C5 PMid: 12707287

28. Mazzali M, Hughes J, Kim YG, Jefferson JA, Kang DH, Gordon KL. Elevated uric acid increases blood pressure in the rat by a novel crystal-independent mechanism. Hypertension. 2001;38(5):1101-6. https://doi.org/10.1161/hy1101.092839 PMid:11711505

29. Nangaku M. Chronic interstitial nephritis. In: Johnson RJ, Feehally J, Floege J, editors. Comprehensive Clinical Nephrology. $5^{\text {th }}$ ed. Philadelphia, PA: Elsevier Saunders, 201. p. 746-58.

30. Goicoechea M, De Vinuesa SG, Vardalles U. Effect of allopurinol in chronic kidney disease progression and cardiovascular risk. Clin J Am Soc Nephrol. 2010;5(8):1388-93. https://doi. 
org/10.2215/CJN.01580210

PMid:20538833

31. Kanbay M, Huddam B, Azak A, Solak Y, Kadioglu GK, Kirbas I. A randomized study of allopurinol on endothelial function and estimated glomerular filtration rate in asymptomatic hyperuricemic subject with normal renal function. Clin J Am Soc Nephrol. 2011;6(8):1887-94. https://doi.org/10.2215/CJN.11451210 PMid:21784838

32. Terawaki H, Nakayama N, Miyazawa E. Effect of allopurinol on cardiovascular incidence among hypertensive nephropathy patients: The gonryo study. Clin Exp Nephrol. 2013;17(4):549-53. https://doi.org/10.1007/s10157-012-0742-z

PMid:23192770

33. Siu YP, Leung KT, Tong MK, Kwan TH. Use of allopurinol in slowing the progression of renal disease through its ability to lower serum uric acid level. Am J Kidney Dis. 2006;47(1):51-9. https://doi.org/10.1053/j.ajkd.2005.10.006

PMid: 16377385

34. Wang H, Wei Y, Kong X, Xu D. Effects of urate-lowering therapy in hyperuricemia on slowing the progression of renal function: A meta-analysis. J Ren Nutr. 2013;23(5):389-96. https://doi. org/10.1053/j.jrn.2012.08.005

PMid:23131573

35. Ito $\mathrm{S}$, Naritomi $\mathrm{H}$, Ogihara $\mathrm{T}$. Impact of serum uric acid on renal function and cardiovascular event in hypertensive patients treated with losartan. Hypertens Res. 2012;35:867-73. https:// doi.org/10.1038/hr.2012.59

PMid:22573200

36. Corry DB, Eslami P, Yamamoto K. Uric acid stimulates vascular smooth muscle cell proliferation and oxidative stress via the vascular renin-angiotensin system. J Hypertens. 2008;26(2):196-75. https://doi.org/10.1097/ HJH.0b013e3282f240bf

PMid:18192841

37. Perlstein TS, Gumieniak O, Hopkins PN. Uric acid and the state of the intrarenal renin-angiotensin system in humans. Kidney Int. 2004;66(4):1465-70. https://doi. org/10.1111/j.1523-1755.2004.00909.x

PMid:15458439

38. Schumacher HR, Becker MA, Wortmann RL. Effect of febuxostat versus allopurinol and placebo in reducing urate in subjects with hyperuricemia and gout: A 28-week, Phase III, randomised, double-blind, parallel-group trial. Arthritis Rheum. 2008;59(11):1540-48. https://doi.org/10.1002/art.24209 PMid:18975369

39. Miao Y, Ottenbros SA, Laverman GD. Effect of a reduction in uric acid on renal outcomes during losartan treatment: A post hoc analysis of the reduction of endpoints in non-insulin dependent diabetes mellitus with the angiotensin II antagonist losartan trial. Hypertension. 2011;58(1):2-7. https://doi.org/10.1161/ HYPERTENSIONAHA.111.171488

PMid:21632472 